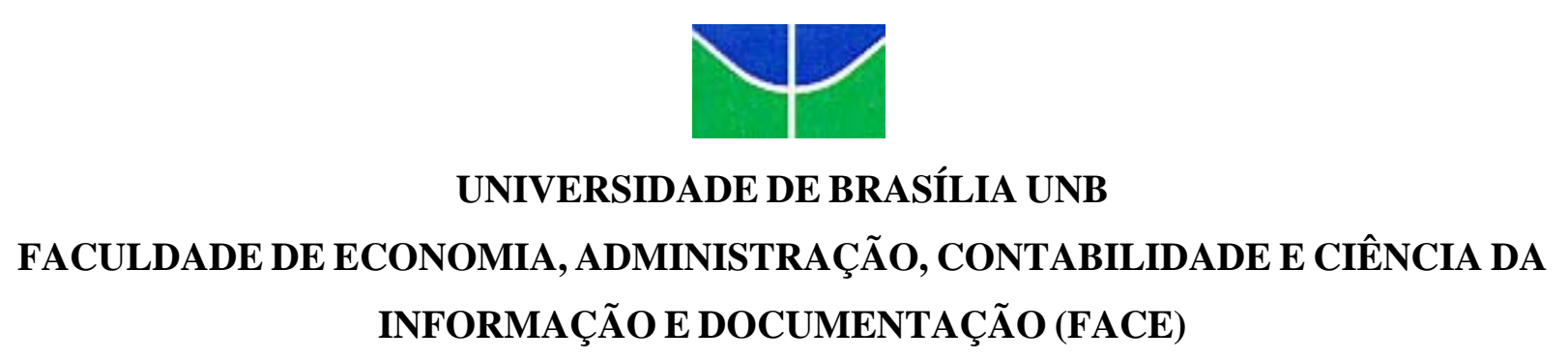

Maurício CÉsar Sousa Matos

\title{
A SATISFAÇÃO NO TRABALHO DO SERVIDOR DO PODER JUDICIÁRIO
}

Brasília - DF 


\section{MAURÍCIO CÉSAR SOUSA MATOS}

\section{A SATISFAÇÃO NO TRABALHO DO SERVIDOR DO PODER JUDICIÁRIO}

Monografia apresentada ao Programa de Pós-Graduação em Administração (PPGA) da Faculdade de Economia, Administração, Contabilidade e Ciência da Informação e Documentação (FACE), da Universidade de Brasília, como requisito parcial à obtenção do grau de Especialista em Gestão Judiciária.

Orientadora: Prof ${ }^{a}$ Dra. Miramar Ramos Maia Vargas

\section{BRASÍLIA - DF}


Com amor, para Leia e o meio filho Luan. 


\section{AGRADECIMENTOS}

Aos meus pais, pela dedicação e esforço com os quais me proporcionaram uma boa educação.

À Professora Miramar Ramos Maia Vargas pela competência, paciência e compreensão dedicadas ao desenvolvimento do projeto.

Aos professores e funcionários da FACE.

Ao STJ pelo investimento financeiro.

Aos colegas da Pós-Graduação, pela amizade e pelos momentos de convivência.

A todos que de alguma forma contribuíram para a realização deste trabalho.

A Deus que sempre me guia e a quem devo tudo isto. 


\section{RESUMO}

Esta Monografia foi elaborada para atender a um dos requisitos exigidos à obtenção do grau de Especialista em Gestão Judiciária. Trata-se de um trabalho de pesquisa que teve por objetivo verificar se os servidores da área de segurança do Superior Tribunal de Justiça (STJ) estão satisfeitos com o seu trabalho. A pesquisa envolveu todos os 143 servidores distribuídos na Secretaria de Segurança nas funções: analista judiciário, técnico Judiciário, requisitados, terceirizados e em exercício provisório. Desse quantitativo, 94 sujeitos responderam ao questionário de pesquisa. A pesquisa utilizou uma abordagem quantitativa, com a aplicação da Escala de Satisfação no Trabalho (EST). Os 143 questionários foram distribuídos para serem respondidos pelos servidores e, posteriormente, depositados em envelopes colocados em pontos estratégicos da unidade. Foram feitas análises descritivas com os dados utilizando-se o SPSS. Os resultados encontrados na pesquisa reforçaram os relatos da literatura que dizem ser a satisfação no trabalho um fenômeno multidimensional, e que os níveis de satisfação do trabalhador podem variar em função dos diferentes aspectos do contexto organizacional. No caso do STJ, foi encontrado que os servidores demonstraram ter um bom nível de satisfação com quatro dos cinco fatores avaliados - colegas de trabalho, salário, chefia e natureza do trabalho. Apenas o fator “promoções” recebeu uma média mais baixa, sinalizando que a Instituição pode investir mais nesse quesito da política de pessoal.

Palavras-Chave: satisfação no trabalho; motivação no trabalho. 


\section{LISTA DE FIGURAS}

Figura 1 - Conseqüências dos vínculos com o trabalho para organizações ............................. 11

Figura 2 - Pirâmide Representando a Hierarquia das Necessidades de Maslow ...................... 16

Figura 3 - Cinco Fatores de Satisfação no Trabalho .............................................................. 30 


\section{LISTA DE QUADROS}

Quadro 1 - Primeiras Visões sobre Motivação 14

Quadro 2 - A Teoria X e a Teoria Y: Concepções a Respeito da Natureza Humana 19

Quadro 3 - Fatores Motivacionais e Fatores Higiênicos.. 20

Quadro 4 - Comparações entre as Visões de Satisfação e Insatisfação 21

Quadro 5 - Descrição dos Itens e Fatores da Escala de Satisfação no Trabalho. 37 


\section{LISTA DE TABELAS}

Tabela 1 - Gênero dos Participantes da Pesquisa ............................................................. 33

Tabela 2 - Faixa Etária dos Participantes da Pesquisa ......................................................... 34

Tabela 3 - Escolaridade dos Participantes da Pesquisa ...................................................... 34

Tabela 4 - Estado Civil dos Participantes da Pesquisa .......................................................... 35

Tabela 5 - Tempo de Serviço no Tribunal dos Participantes da Pesquisa ............................ 35

Tabela 6 - Tipo de Vínculo Empregatício ............................................................................. 36

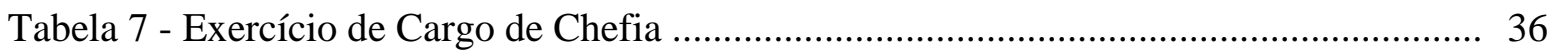

Tabela 8 - Média e Desvio Padrão dos Fatores do Instrumento de Satisfação no trabalho.... 39

Tabela 9 - Média e Desvio Padrão dos Itens do Instrumento Satisfação no Trabalho............ 41 


\section{SUMÁRIO}

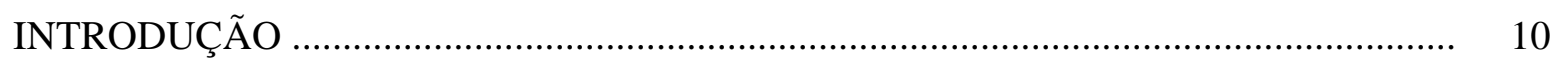

CAPÍTULO 1- REFERENCIAL TEÓRICO ……………………………………….... 13

1.1 - A Motivação no Trabalho ........................................................................................... 13

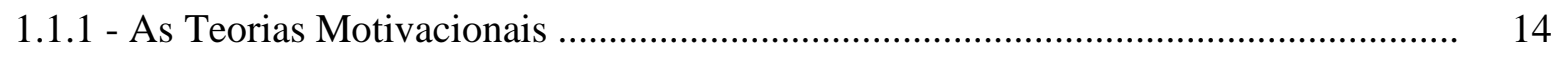

1.2 - A Satisfação no Trabalho .................................................................................... 28

1.2.1 - Os Fatores da Satisfação no Trabalho ................................................................... 29

CAPÍTULO 2 - ASPECTOS METODOLÓGICOS DA PESQUISA ……………………... 32

2.1 - Tipo de Pesquisa …………………………………..................................

2.2 - Contexto da Pesquisa …………………………………………………….... 32

2.3 - Participantes da Pesquisa ................................................................................ 33

2.4 - Instrumento da Pesquisa ..................................................................................... 36

2.5 - Procedimentos de Coleta de Dados ........................................................................ 38

2.6 - Análise de Dados .............................................................................................. 38

CAPÍTULO 3 - APRESENTAÇÃO DOS RESULTADOS …………………………….... 39

3.1 - A Satisfação no Trabalho do Servidor do Poder Judiciário............................................ 39

3.2 - Subsídios para a Política de Pessoal do STJ ............................................................ 42

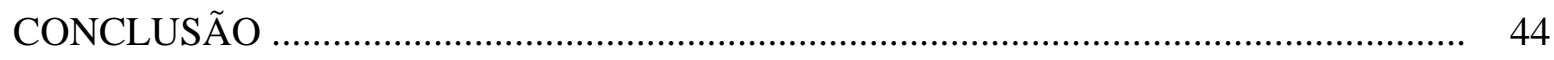

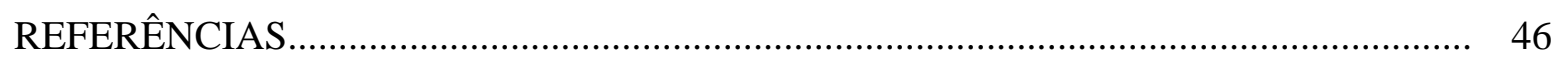

Anexo "A" - Instrumento de Pesquisa ……………………………………………...... 48 


\section{Introdução}

A relação entre homem e trabalho tem sido objeto de estudo por mais de um século pela comunidade científica. Para Bergamini (1997) essa relação já existia mesmo antes da revolução industrial, onde a maneira de motivar consistia no uso de punições e prêmios. Com a industrialização, afirma a autora, se passou a exigir uma maior eficiência nos processos industriais (automação, tarefas repetitivas e rotineiras, divisão no trabalho). Por sua vez, o trabalhador passou a exigir maiores recompensas e melhores condições de trabalho. Com isso as relações interpessoais tiveram um maior destaque, tendo uma maior abertura nos canais de comunicação.

Silva e Rodrigues (2007) destacam que trabalhadores e administração, nos dias atuais, passam por novos desafios. Um novo processo de adaptação, decorrente dos avanços tecnológicos, onde se procura uma estratégia que melhor lhes permitam dominar esse cenário. As organizações são obrigadas a modificar sua maneira de entender o papel desempenhado pelo indivíduo, que de sua parte, procura também reformular as suas crenças e suposições a respeito do papel que o trabalho desempenha em suas vidas. Neste momento, torna-se muito importante compreender, de uma forma mais aprofundada, aquilo que é preciso saber sobre a complexidade do comportamento motivacional do indivíduo, bem como que fatores contribuem para a sua satisfação no trabalho.

Durante as décadas de 1960 e 70, afirmam Siqueira e Gomide Júnior (2004), ocorreram alterações significativas na compreensão de fatores capazes de influenciar resultados organizacionais advindos da força de trabalho. Satisfação e envolvimento com o trabalho dominaram as pesquisas que buscavam identificar possíveis antecedentes que participariam da predição de níveis de produtividade e desempenho, bem como de taxas de absenteísmo e de rotatividade no trabalho.

Ainda segundo Siqueira e Gomide Júnior, esses estudos tinham por objetivo aumentar a compreensão do comportamento humano no trabalho. Essa produção teórica passou também a ser usada no processo de desenvolvimento gerencial, para que os dirigentes pudessem planejar estratégias capazes de levar os trabalhadores a se tornarem satisfeitos e envolvidos com o trabalho. A Figura 1 apresenta o esquema idealizado por Siqueira e Gomide Júnior (2004): 


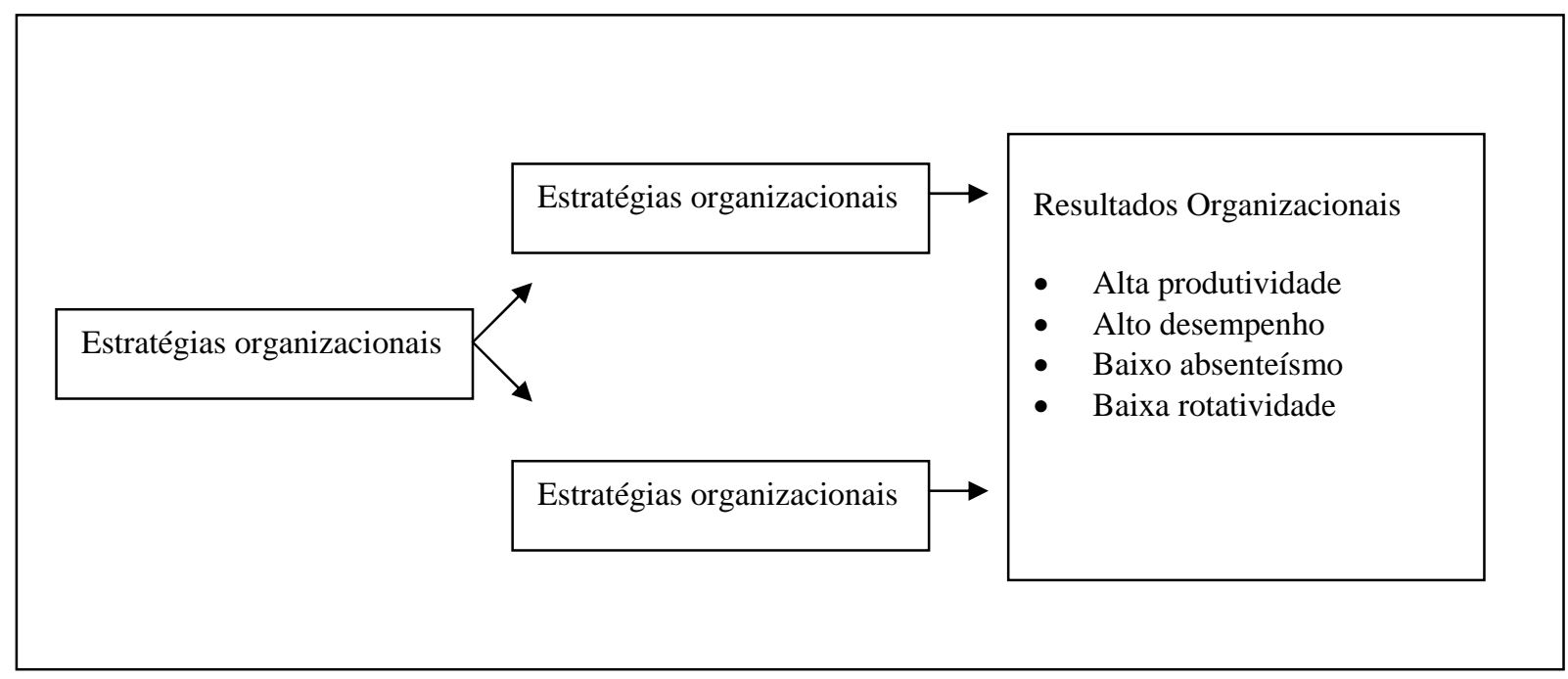

Figura 1 - Conseqüências dos vínculos com o trabalho para organizações

Fonte: Siqueira e Gomide Júnior (2004)

De acordo com Siqueira e Gomide Júnior (2004), são muitos os estudos feitos para se desvendar as dimensões, os determinantes (possíveis causas), os correlatos (conceitos semelhantes), as conseqüências (possíveis efeitos) e desenvolver técnicas de mensuração de um sentimento que emerge quando o homem se relaciona com situações do seu contexto de trabalho. Esse sentimento, afirma Siqueira e Gomide Júnior, denomina-se “satisfação no trabalho” e tem sido a variável de natureza afetiva que maior atração tem exercido sobre os pesquisadores da área organizacional.

Na visão de Estefano (1996), são raras as organizações que se dão conta dos riscos acarretados pela vulnerabilidade dos seus ativos humanos. Isso porque os sistemas contábeis não conseguem captar os ganhos ou prejuízos decorrentes do maior ou menor grau de satisfação das pessoas no trabalho. A autora lembra que os recursos humanos são fundamentais em qualquer tipo de organização, seja ela industrial, comercial, do setor privado ou do setor público.

No Brasil, percebe-se no Poder Judiciário um aumento constante de processos, fato amplamente divulgado pelas mídias. Essa necessidade requer um esforço cada vez maior dos servidores do judiciário, de forma a organizar e manter a qualidade dos serviços que a Instituição é capaz de fornecer. Observa-se, assim, que os órgãos do judiciário, como toda e qualquer organização, dependem muito do fator humano para garantir a eficácia dos seus serviços. 
Essa constatação e a escassez de estudos que investiguem a satisfação do trabalhador no contexto do judiciário brasileiro levaram à formulação do seguinte problema de pesquisa: "Quais são os determinantes da satisfação no trabalho do servidor judiciário”? A pesquisa teve os seguintes objetivos:

\section{Geral}

- Investigar os fatores que promovem satisfação e insatisfação no trabalho do servidor judiciário.

\section{Específicos}

- Revisar a literatura sobre Satisfação no Trabalho.

- Verificar, na percepção dos servidores do judiciário, os fatores responsáveis pela satisfação e insatisfação no trabalho.

- Fornecer subsídios para melhoria da política de pessoal da Instituição pesquisada.

O trabalho tem que ser fonte de prazer e não de sofrimento para o homem. Siqueira e Gomide Júnior (2004) salientam que muitos estudos enfatizam a importância da satisfação no trabalho para além das fronteiras do contexto organizacional. Vários autores argumentam ser a satisfação um resultado de experiências pessoais no meio organizacional que se irradiam para a vida social do indivíduo, podendo representar um forte indicador de influências do trabalho sobre saúde mental, de relação entre trabalho e vida familiar ou até de interação entre trabalho e vínculos afetivos pessoais.

As diversas instâncias judiciais estão passando, no momento, por um processo de mudança de cultura organizacional, em razão de demandas impostas pelo próprio Estado e a sociedade em geral. Assim, conhecer os determinantes da satisfação do trabalhador do judiciário poderá fornecer subsídios interessantes para a gestão desse processo de mudança. Soma-se a isso o fato de que há, na literatura, muitos estudos sobre a satisfação no trabalho, entretanto poucos focam esse fenômeno dentro do contexto do Poder Judiciário.

Seguindo a estrutura recomendada para uma Monografia, a apresentação do trabalho ficou dividida em quatro partes: Capítulo 1 - Referencial Teórico; Capítulo 2 - Aspectos Metodológicos da Pesquisa; Capítulo 3 - Apresentação e Discussão dos Resultados; Conclusão. 


\section{Capítulo 1 - Referencial Teórico}

O foco deste Capítulo é revisar a literatura da área de Satisfação no Trabalho, com o objetivo de fornecer suporte teórico à pesquisa empírica realizada. Primeiramente, será feita uma breve revisão do tema "Motivação no Trabalho", pois foi observado que os diversos estudos pesquisados sobre "Satisfação no Trabalho” fazem também uma discussão sobre as principais teorias motivacionais.

\section{1 - A Motivação no Trabalho}

Tecnicamente, o termo motivação deriva originalmente da palavra latina motivus, movere, que significa mover. Esta acepção evidencia-se na definição de Berelson e Steiner (1964 apud LOPES, 1980, p.3): "Um motivo é um estado interno que dá energia, torna ativo ou move (daí motivação) e que dirige ou canaliza o comportamento em direção a objetivos".

Segundo Bergamini (1990), a motivação se origina das carências internas que predispõem o indivíduo a um comportamento de busca, que tem como finalidade satisfazê-la. Trata-se de um ciclo interno que tem um início e um fim dentro do próprio mundo interior de cada pessoa e só pode ser entendido como algo interior a ela. Destaca que o ser humano jamais estará completamente satisfeito, pois existirá sempre uma necessidade não satisfeita que organizará ou dirigirá novas condutas motivacionais. De acordo com seu ponto de vista, a satisfação de necessidades humanas passadas não torna o homem passivo e acomodado à vida; pelo contrário, ela predispõe a iniciativa mais ousada rumo à sua auto-realização e assim, jamais se atinge um estado de plena saciação.

Robins (2002) define motivação como o processo responsável pela intensidade, direção e persistência dos esforços de uma pessoa para o alcance de uma determinada meta.

Silva e Rodrigues (2007) afirma que o estudo da motivação e do comportamento é uma busca de respostas para perguntas complexas a respeito da natureza humana. Que, fundamentalmente, nosso comportamento é motivado por um desejo de atingir algum objetivo. 


\title{
1.1.1 - As Teorias Motivacionais
}

\author{
Stoner e Freeman ( 1999) relatam que as primeiras teorias da motivação possuíam
} aspectos muito semelhantes, pois todas elas buscavam construir um modelo único de motivação que pudesse ser aplicado a qualquer tipo de trabalhador e em qualquer tipo de situação. No Quadro 1, apresentado a seguir, os autores fazem uma síntese das primeiras visões sobre a motivação, feita com base no trabalho de Steers e Porter (1983).

\begin{tabular}{|c|c|c|}
\hline MODELO TRADICIONAL & $\begin{array}{l}\text { MODELO DAS RELAÇÕES } \\
\text { HUMANAS }\end{array}$ & $\begin{array}{l}\text { MODELO DOS RECURSOS } \\
\text { HUMANOS }\end{array}$ \\
\hline \multicolumn{3}{|c|}{ Suposições } \\
\hline $\begin{array}{l}\text { O trabalho é inerentemente } \\
\text { desagradável para a maioria das } \\
\text { pessoas. } \\
\text { O que elas fazem é menos } \\
\text { importante do que aquilo que } \\
\text { ganham para fazê-lo. } \\
\text { Poucas desejam ou podem realizar } \\
\text { trabalho que exija criatividade, } \\
\text { autodirecionamento ou auto- } \\
\text { controle. }\end{array}$ & $\begin{array}{l}\text { As pessoas desejam sentir-se úteis } \\
\text { e importantes. } \\
\text { As pessoas desejam participar, ser } \\
\text { reconhecidas como indivíduos. } \\
\text { Essas necessidades são mais } \\
\text { importantes do que o dinheiro para } \\
\text { motivar as pessoas no trabalho. }\end{array}$ & $\begin{array}{l}\text { O trabalho não é inerentemente } \\
\text { desagradável. As pessoas desejam } \\
\text { contribuir para os objetivos } \\
\text { significativos que ajudaram } \\
\text { estabelecer. } \\
\text { A maioria das pessoas pode } \\
\text { exercer muita mais criatividade, } \\
\text { autodirecionamento em auto- } \\
\text { controle do que os trabalhos atuais } \\
\text { demandam. }\end{array}$ \\
\hline \multicolumn{3}{|c|}{ Políticas } \\
\hline 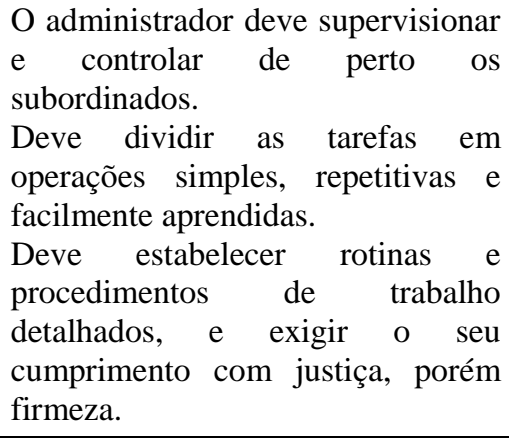 & $\begin{array}{l}\text { O administrador deve fazer com } \\
\text { que cada trabalhador se sinta útil e } \\
\text { importante. } \\
\text { Deve manter os subordinados } \\
\text { informados e ouvir as objeções que } \\
\text { fizeram aos seus planos. } \\
\text { O administrador deve permitir que } \\
\text { os subordinados exercitem algum } \\
\text { auto-direcionamento e auto- } \\
\text { controle em questões rotineiras. }\end{array}$ & $\begin{array}{l}\text { O administrador deve aproveitar } \\
\text { recursos humanos subutilizados. } \\
\text { Deve criar um ambiente onde } \\
\text { todos os membros possam } \\
\text { contribuir dentro dos limites de } \\
\text { sua capacidade. } \\
\text { Deve encorajar a participação total } \\
\text { em assuntos importantes, } \\
\text { ampliando continuamente o auto- } \\
\text { direcionamento e auto-controle } \\
\text { dos subordinados. }\end{array}$ \\
\hline \multicolumn{3}{|c|}{ Expectativas } \\
\hline $\begin{array}{l}\text { As pessoas podem tolerar o } \\
\text { trabalho caso a remuneração seja } \\
\text { decente e o chefe seja justo. } \\
\text { Se as tarefas forem suficiente } \\
\text { simples e as pessoas controladas de } \\
\text { perto, elas irão produzir de acordo } \\
\text { com os padrões. }\end{array}$ & $\begin{array}{l}\text { Compartilhar as informações com } \\
\text { os subordinados e envolve-los nas } \\
\text { decisões de rotina irá satisfazer } \\
\text { suas necessidades básicas de } \\
\text { participação e valorização. } \\
\text { Satisfazer essas necessidades irá } \\
\text { aumentar o "moral” e reduzir a } \\
\text { resistência à autoridade formal - os } \\
\text { subordinados irão "cooperar de boa } \\
\text { vontade". }\end{array}$ & $\begin{array}{l}\text { Expandir a influência, o auto- } \\
\text { direcionamento e o auto-controle } \\
\text { dos subordinados irá levar a } \\
\text { melhorias diretas na eficiência } \\
\text { operacional. } \\
\text { A satisfação do trabalho pode } \\
\text { aumentar com "subproduto" da } \\
\text { utilização total dos seus recursos } \\
\text { pelos subordinados. }\end{array}$ \\
\hline
\end{tabular}

Quadro 1 - Primeiras visões sobre a motivação .

Fonte: Steers e Porter (1983 apud STONER; FREEMAN, 1999). 
De acordo com Tamayo e Paschoal (2003) numerosas teorias foram elaboradas para tentar explicar a motivação no trabalho. Inicialmente, as explicações eram relativamente simples, baseadas em uma única dimensão que não levava em consideração a dinâmica entre empregado e trabalho. A partir do modelo econômico do homem, proposto por Taylor, foram elaboradas muitas outras, com maior complexidade e uma abordagem cada vez mais psico-sócio-cultural.

Em razão da dificuldade em comparar o grande número de teorias gerais e específicas que existem sobre "motivação” no trabalho, Campbell (1970 apud LOBOS, 1975) apresentou um esquema de classificação que reduz esta confusão assinalando teorias motivacionais de “conteúdo” e de "processo” em separado.

\section{a) - Teorias Motivacionais de Conteúdo}

Segundo Lobos (1975), as teorias motivacionais “de conteúdo” englobam especificamente variáveis individuais ou situacionais que se supõem responsáveis pela conduta. Para Stoner e Freeman (1999), tais teorias concentram-se nas necessidades internas que motivam o comportamento. Para eles, as pessoas agem de determinadas maneiras num esforço para reduzir ou satisfazer suas necessidades. Esta abordagem é associada a pensadores como Maslow, Alderfer, Mcgregor, Herzberg e McClelland, cujos pressupostos serão apresentados a seguir:

\section{Maslow - Teoria da Hierarquia de Necessidade}

A Teoria da Hierarquia de Necessidades de Abraham Maslow é, talvez, a mais conhecida teoria de motivação existente. Para Maslow (apud RoBBins, 2002) dentro de cada ser humano existe uma hierarquia de cinco necessidades, a saber: 


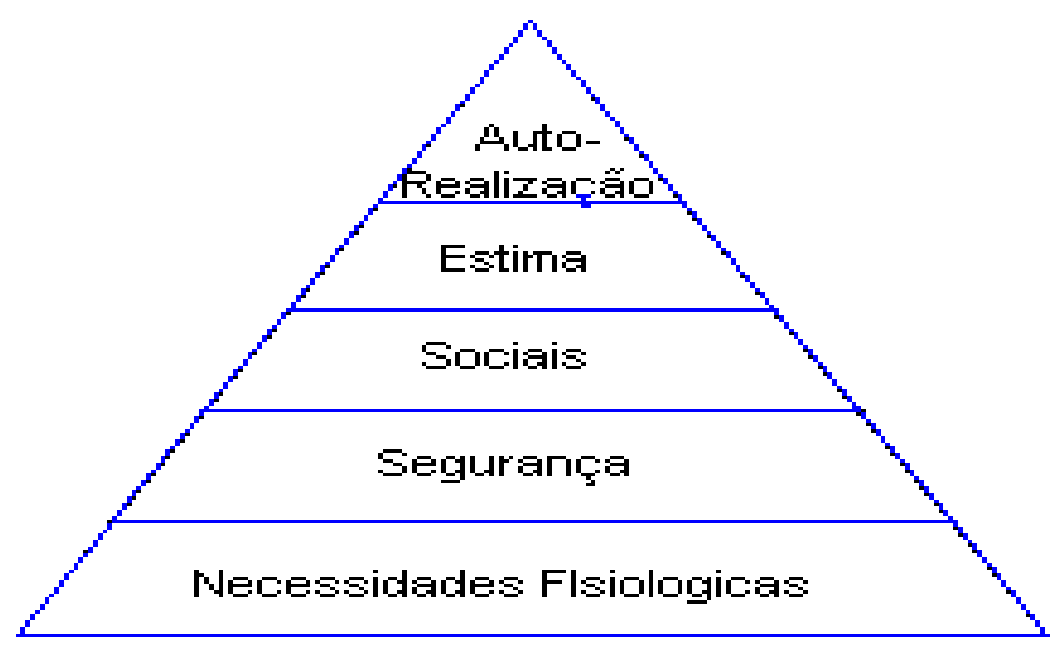

Figura 2 - Pirâmide Representando a Hierarquia das Necessidades de Maslow. Fonte: Robbins (2002).

1. Fisiológicas: incluem fome, sede, abrigo, sexo e outras necessidades corporais;

2. Segurança: incluem segurança e proteção contra mal físico ou emocional;

3. Sociais: inclui afeto, relacionar-se com alguém, aceitação e amizade;

4. Estima: incluem fatores internos de estima, amor-próprio, autonomia e realização; e fatores; externos como status, reconhecimento e atenção;

5. Auto-realização: o impulso de alguém tornar-se o que é capaz de se tornar, inclui crescimento, atingimento de seu potencial e auto-realização.

As necessidades fisiológicas e de segurança foram descritas como necessidades de baixa ordem e as necessidades sociais de estima e auto-realização como necessidades de alta ordem. A diferença entre as duas ordens foi feita na pressuposição de que necessidades de alta ordem são satisfeitas internamente dentro da pessoa, enquanto que as necessidades de baixa ordem são predominantemente satisfeitas externamente por coisas como pagamento, contrato com sindicatos, tempo de serviço.

Segundo Robbins (2002), Maslow acreditava que uma necessidade substancialmente satisfeita não motiva mais. Então; para motivar alguém, é preciso entender em que nível de hierarquia àquela pessoa está atualmente e concentrar-se em satisfazer as necessidades daquele nível ou acima dele. A Teoria de Maslow, apesar de bastante coerente, não leva em conta que, na 
prática, todas as necessidades tendem a atuar simultaneamente. O próprio Maslow admitiu existirem numerosas exceções no tocante a esta seqüência hierárquica.

Lobos (1975) afirma que várias pesquisas não conseguiram confirmar cientificamente a teoria de Maslow e algumas delas até mesmo a invalidaram. A sua ampla aceitação talvez esteja na sua validade de "sentido comum". No entanto, como teoria motivacional, a teoria das necessidades básicas apresenta dois aspectos debilitados, que são:

\section{Aldefer - A Teoria ERC}

Stoner e Freeman (1999) esclarecem que essa teoria foi uma tentativa de aprimorar a hierarquia de Maslow. Com base na análise das categorias propostas por Maslow, bem como do seu próprio trabalho, Alderfer dividiu as necessidades em apenas três categorias:

- necessidades básicas de existência ou sobrevivência,

- necessidades de relacionamento, que tratam da interação social e dos aspectos externos de estima (reconhecimento e status por parte dos outros);

- necessidades de crescimento, que enfocam o desejo de uma pessoa de realizar e desenvolver seu potencial, bem como a satisfação do ego (sucesso e autonomia).

As três primeiras letras das categorias formam a sigla ERG (existence, relatedness,e growth).

De acordo com Alderfer (1969 apud STONER E FREEMAN, 1999) quando as necessidades mais altas são frustadas, as necessidades inferiores retornam, mesmo já tendo sido satisfeitas, ao contrário de Maslow, que acreditava que uma necessidade uma vez satisfeita perdia seu poder de motivação. Enquanto Maslow via as pessoas subindo sempre em sua hierarquia, Alderfer via as pessoas subindo ou descendo de tempos em tempos e de situação em situação.

Para Bowditch (2004), embora Aldefer notasse que havia uma progressão de um estágio pra outro, havia uma certa sobreposição entre eles e as pessoas podiam passar de um estágio pra outro sem ter plenamente satisfeito o primeiro, o que torna difícil avaliar sua aplicação a situações organizacionais ou até mesmo na realização pessoal dos empregados. 


\section{McGregor - A Teoria " $X$ ” e a Teoria " $Y$ "}

McGregor (1966 apud Bergamini, 1998) lança a idéia de que os trabalhadores são, por natureza, laboriosos, fazendo todo o possível para atingir sua própria auto-realização através do trabalho. Conseqüentemente, a empresa, segundo esse autor, deve dispor de recursos que facilitem o amadurecimento motivacional de seus assalariados. Para ele, se as pessoas forem impedidas de satisfazer suas necessidades através do trabalho, comportar-se-ão com indolência, passividade e má vontade, ficando sob a responsabilidade da empresa os níveis de imaturidade motivacional dos seus trabalhadores. É como se essas organizações acabassem presas aos laços que elas mesmas preparam.

McGregor (1960 apud RoBBins, 2002) propôs duas visões distintas do ser humano: uma basicamente negativa, chamada de Teoria $\mathbf{X}$, e outra positiva, chamada de Teoria Y. Depois de observar a forma como os executivos tratavam seus funcionários, McGregor concluiu que a visão que os executivos têm da natureza dos seres humanos se baseia em certos agrupamentos de premissas, e que eles tendem a moldar seu próprio comportamento em relação aos funcionários de acordo com elas. As premissas da Teoria X são as seguintes:

- Os funcionários, por natureza, não gostam de trabalhar e, sempre que possível, tentarão evitar o trabalho.

- Como eles não gostam de trabalhar, precisam ser coagidos, controlados ou ameaçados com punições para que atinjam as metas.

- Os funcionários evitam responsabilidades e buscam orientação formal sempre que possível.

- A maioria dos trabalhadores coloca a segurança acima de todos os fatores associados ao trabalho e mostra pouca ambição.

Em contraste com essas visões negativas, McGregor lista as quatro premissas positivas, sob a chamada Teoria Y:

- Os funcionários podem achar o trabalho algo tão natural quanto descansar ou se divertir. 
- As pessoas demonstrarão auto-orientação e autocontrole se estiverem comprometidas com os objetivos.

- As pessoas, na média, podem aprender a aceitar, ou até a buscar, a responsabilidade.

- A capacidade de tomar decisões inovadoras pode estar em qualquer pessoa, não sendo um privilégio exclusivo daquelas em posições hierárquicas mais altas.

As implicações motivacionais da análise de McGregor (1960 apud RoBBINS, 2002) podem ser mais bem expressas pela estrutura apresentada por Maslow (1954). A Teoria X assume que as necessidades de nível baixo dominam os indivíduos; a Teoria Y, que as necessidades de nível alto dominam. McGregor pessoalmente, acreditava que as da teoria Y eram mais válidas que as da Teorias X. Para maximizar a motivação dos funcionários, propôs idéias como a do processo decisório participativo, as das tarefas desafiadoras e com muita responsabilidade e a de um bom relacionamento de grupo. O Quadro 1 mostra a comparação entre as Teorias X e Y:

\begin{tabular}{|l|l|}
\hline \multicolumn{1}{|c|}{ Pressuposições da Teoria X } & \multicolumn{1}{c|}{ Pressuposições da Teoria Y } \\
\hline Desprazer em trabalhar. & O trabalho é meio de satisfação \\
\hline Pessoas controladas constantemente & Autocontrole e autonomia. \\
\hline Punição como estímulo & Reconhecimento como estímulo \\
\hline Rigidez. & Flexibilidade \\
\hline Desejo pela segurança e pouca ambição. & Busca pelo desenvolvimento \\
\hline As pessoas evitam responsabilidade & As pessoas buscam desafios \\
\hline
\end{tabular}

Quadro 2- A Teoria X e a Teoria Y: diferentes concepções a respeito da natureza humana Fonte: Robbins (2002)

\section{Herzberg - Teoria dos Dois Fatores}

Stoner e Freeman (1999) apontam que outra importante teoria clássica é a Teoria da Motivação-Higiene, proposta pelo psicólogo Frederick Herzberg no final da década de 1950. Para Stoner e Freeman, o ponto crucial dessa teoria é que existem dois diferentes conjuntos de fatores no trabalho. Um conjunto de fatores que pode fazer e motivar as pessoas. O outro que pode apenas evitar a insatisfação. Herzberg formulou a teoria dos dois fatores para explicar o 
comportamento das pessoas em situação de trabalho. Para ele existem dois fatores que orientam o comportamento das pessoas:

Fatores motivacionais ou fatores intrínsecos estão relacionados ao conteúdo do cargo e com a natureza que a pessoa executa. Eles envolvem auto-realização, reconhecimento, progresso, responsabilidade. Quando são ótimos provocam a satisfação da pessoa. Porém, quando precários, evitam a satisfação. Daí, Herzberg os chama de fatores satisfacientes.

Fatores higiênicos ou fatores extrínsecos estão localizados no ambiente que rodeiam as pessoas e abrangem as condições dentro quais elas desempenham seu trabalho. Estão fora do controle das pessoas, pois são decididas pela empresa. Tais fatores são: salário, benefícios sociais, estilos de chefias ou supervisão, políticas e diretrizes da empresa, regulamento, condições físicas e ambientais do trabalho etc. O Quadro 3 ilustra os dois tipos de fatores propostos por Herzberg:

\begin{tabular}{|l|l|}
\hline \multicolumn{1}{|c|}{ FATORES MOTIVACIONAIS } & \multicolumn{1}{c|}{ FATORES HIGIÊNICOS } \\
\hline O trabalho em si & Condições de trabalho \\
\hline Responsabilidade & Benefícios \\
\hline Realização & Administração da empresa \\
\hline Reconhecimento & Segurança no trabalho \\
\hline Progresso Funcional & Relação com o supervisor \\
\hline
\end{tabular}

Quadro 3 - Fatores Motivacionais e Fatores Higiênicos

Fonte: Stoner e Freeman (1999)

Para Bergamini (1998), a importância desse tipo de pesquisa é permitir que se perceba a diferença entre os fatores chamados de higiene, que não motivam, mas tão somente neutralizam a insatisfação e aqueles que representam a verdadeira fonte de satisfação motivacional. Com isso, Herzberg conclui que o contrário de insatisfação não é satisfação, mas nenhuma satisfação. Assim como o contrário de satisfação, não é insatisfação, mas nenhuma satisfação. Isso significa dizer que aquilo que deixa uma pessoa insatisfeita quando está ausente, não as satisfaz quando presente. E aquilo que deixa as pessoas satisfeitas quando presente, não as deixa insatisfeitas quando ausente. Herzberg tentou demonstrar que não basta oferecer fatores de higiene para se obter motivação. Atendidos os fatores periféricos está se garantindo apenas o bem estar físico das pessoas. É necessário ir além disso, e oferecer às pessoas oportunidade de garantir sua chegada aos objetivos de satisfação interior, responsáveis pela verdadeira motivação. 
De acordo com Lobos (1975) como teoria motivacional, o enfoque de Herzberg apresenta debilidades importantes que têm sido largamente discutidas, por exemplo: a) a metodologia utilizada é discutível; b) uma reanálise posterior de dados apresentou inconsistência e contradição a respeito de outras evidências da pesquisa original e c) a teoria não explica o processo pelo qual os fatores "motivadores” provocam a motivação. Sem tal explicação a teoria deixa de ser motivacional e passa a ser, simplesmente, uma teoria de satisfação no trabalho.

Robbins (2005) fez uma comparação entre algumas das principais visões que tratam sobre a satisfação e a insatisfação no ambiente de trabalho. Essa comparação é mostrada no Quadro 4:

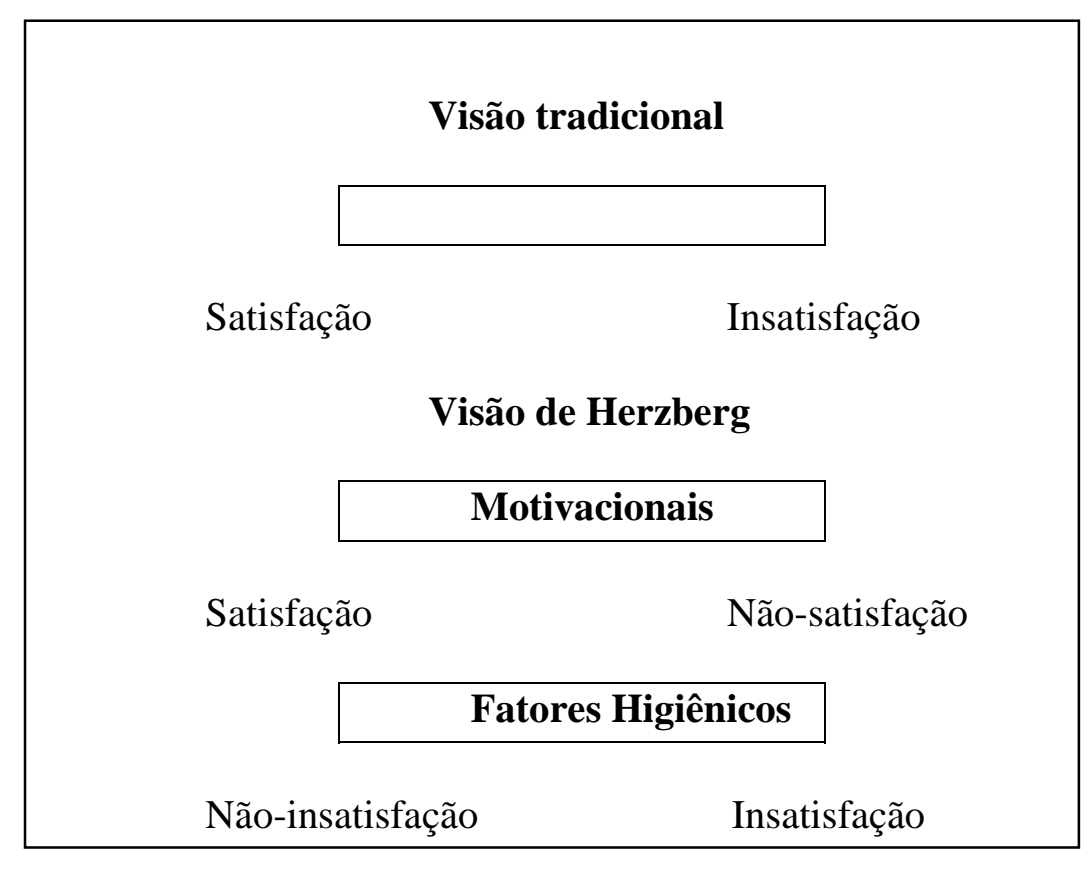

Quadro 4 - Comparações entre as visões de Satisfação e Insatisfação Fonte: Robbins (2005)

\section{McClelland - Teoria das Necessidades}

A Teoria de necessidades de McClelland (1961) (apud RoBBINS, 2002) foi desenvolvida por David McClelland e seus associados. A teoria enfoca três necessidades: realização, poder e afiliação. Elas são definidas como se segue: 
- Necessidade de realização: o impulso de exceder, de sair-se bem em relação a um conjunto de padrões, de lutar pelo sucesso.

- Necessidade de poder: a necessidade de fazer os outros se comportarem de uma maneira que eles não teriam se comportado de outro modo.

- Necessidade de afiliação: o desejo por relações interpessoais amigáveis e próximas.

Da pesquisa sobre necessidade de realização, McClelland (1961apud RoBBINS, 2002) descobriu que indivíduos altamente realizadores diferenciavam-se dos outros pelo seu desejo de fazer as coisas de forma melhor. Eles procuram situações em que possam alcançar responsabilidade pessoal para encontrar soluções para os problemas e que possam receber rápido retorno sobre seus desempenhos. Indivíduos altamente realizadores preferem o desafio de trabalhar num problema e aceitar a responsabilidade pessoal pelo seu sucesso ou fracasso, em vez de deixar o resultado para o acaso ou para ações de outros.

A necessidade de poder é o desejo de ter impacto, de ser influente e de controlar os outros. Indivíduos com elevada necessidade de poder apreciam estar "no controle", lutam para ter influência sobre os outros, preferem ser colocados em situações competitivas e orientadas a status e tendem a ser mais preocupados com prestígio e a ter influência sobre outros do que com um desempenho eficaz.

A terceira necessidade isolada por McClelland (1961 apud RoBBins, 2002) é a de afiliação. Esta necessidade recebeu menos atenção dos pesquisadores. Afiliação pode ser definida como o desejo de ser apreciado e aceito pelos outros. Indivíduos com alta motivação de afiliação lutam por amizades, preferem situações de cooperação em vez das de competição e desejam relacionamentos que envolvam um alto grau de compreensão mútua.

Respaldadas por um extenso número de pesquisas, algumas previsões, razoavelmente bem-sustentadas, podem ser feitas com base no relacionamento entre necessidade de realização e desempenho no trabalho. Embora menos pesquisas tenham sido feitas sobre necessidades de poder e afiliação, existem descobertas coerentes aqui, também (RoBBins, 2002):

Primeira, indivíduos com alta necessidade de realização preferem situações de trabalho com responsabilidade pessoal, retorno e um grau intermediário de risco. Quando estas características forem predominantes, os indivíduos altamente realizadores estarão fortemente 
motivados. A evidência demonstra com constância que, por exemplo, indivíduos altamente realizadores têm sucesso em atividades empreendedoras como dirigir seus próprios negócios e gerenciar uma unidade independente dentro de uma grande organização.

Segunda, uma elevada necessidade de realizar não leva, necessariamente, a ser um bom gerente, sobretudo em grandes organizações. Pessoas com uma necessidade de realização elevada estão interessadas em quão bem elas estão se saindo pessoal, e não em influenciar outros a se saírem bem. Vendedores realizadores não necessariamente dão bons gerentes de vendas, e o bom gerente geral numa grande organização não tem, normalmente, uma elevada necessidade de realizar.

Terceira, as necessidades de afiliação é poder tendem a estar relacionadas de perto com o sucesso gerencial. Os melhores gerentes têm elevadas necessidades de poder e baixas necessidades de afiliação. Na verdade, uma motivação de poder elevada pode ser um requisito para a eficácia gerencial. Tem sido sugerido que uma necessidade de poder elevada pode ocorrer simplesmente como uma função do nível de alguém numa organização hierárquica.

O último argumento propõe que, quanto mais alto o nível que um indivíduo sobe numa organização, maior é a motivação de poder do ocupante. Em resultado, posições poderosas seriam o estímulo a uma motivação de poder elevada.

A alta necessidade de realização também pode ser estimulada pelo medo do fracasso, afirmam Stoner e Freeman (1999). Os empregados podem ser fortemente motivados a agir pelo seu medo de não alcançar os objetivos pessoais ou da organização, e pelo seu medo de um possível constrangimento público quando esses fracassos forem reconhecidos. Já para alguns indivíduos, o medo do sucesso pode ser uma motivação. Essas pessoas temem a tensão e o peso do sucesso, e a inveja e a antipatia que ele pode despertar nos outros.

Na opinião de Lobos (1975), as maiores críticas feitas à teoria da motivação pelo êxito e/ou medo do fracasso são as seguintes:

1. A estabilidade das respostas dos indivíduos através do tempo e diferentes tipos de motivação é baixa. Logo, os resultados analisados por meio de técnicas projetivas, especialmente o teste da Percepção Temática, podem não ser consistentes.

2. A grande proporção da pesquisa, sobre motivação pelo êxito, têm sido realizada com estudantes universitários. Em situação real de trabalho, devido a grande variedade de variáveis aparentem, os resultados podem ser diferentes. 
Bowditch (2004) destaca que um ponto importante no trabalho de McClelland, onde ele sugere que as pessoas podem ser ensinadas a ter certas necessidades. Como exemplo, para se aumentar a motivação entre gerentes e subordinados poderiam ser desenvolvidos programas de treinamento para aumentar a motivação baseado em dois pontos:

- A motivação é mutável, ainda que na idade adulta.

- A motivação se torna uma variável dependente, ao contrário das teorias anteriores, nas condições antecedentes ao desenvolvimento de uma necessidade particular.

\section{b) Teorias Motivacionais de Processo}

De acordo com Bowdicht (2004), embora as teorias conteúdo enfatizam a compreensão das necessidades em determinado instante e não na previsão do comportamento, foram desenvolvidas, para isso, outras teorias para explicar mais plenamente o processo de motivação em termos dos fatores que dirigem o comportamento.

\section{A Teoria do Acionamento}

É uma das teorias motivacionais mais antigas e populares entre os psicólogos. Segundo Lobos (1975), esta lei sustenta que as respostas associadas a um estado de satisfação, têm maior possibilidade de ocorrer do que aquelas associadas a um estado de desconformidade. Neste caso, a conduta presente está mais ligada determinada pela experiência do que pela antecipação futura do acontecimento. Para ele, em razão das pesquisas ter sido realizadas mais na análise do comportamento animal, consideraram então os acionamentos como de ordem animal fisiológica. Considerando a força do impulso como uma função do período de tempo em que o animal foi privado de uma certa necessidade fisiológica.

O acionamento tem sido definido como uma conduta provocada por estímulos ambientais imediatos, enquanto a força do hábito seria o vínculo que existe entre um estímulo e uma resposta; isto é, a conexão que influencia o tipo de conduta que deve ser ativado por um determinado impulso. 


\section{A Teoria das Expectativas}

Para Lobos (1975), esta teoria tem seu início nos trabalhos independentes de Lewin e de Tolman nos anos 30. Após observarem pessoas e animais, ambos cientistas desenvolveram os elementos da teoria cognitiva. O principal foco da pesquisa é a noção de que os indivíduos têm expectativas acerca dos resultados que advirão em conseqüência de suas ações. Em razão de certos resultados, as pessoas elegem condutas, dentre as alternativas, de acordo com as probabilidades de ocorrência e o valor que se atribui a estes resultados.

Lobos (19975) afirma que tal teoria baseia-se na premissa de que a motivação para o desempenho que um indivíduo possui apóia-se na antecipação que ele faz de eventos futuros. Ou seja, o indivíduo tem expectativas acerca dos resultados que advirão em conseqüência de suas ações. A teoria indica que ele faz a escolha entre as condutas alternativas de acordo com as probabilidades de ocorrência e o valor que se atribui a estes resultados.

Nesta corrente de pensamento, destaca-se o trabalho de Vroom (1964 apud BERGAMINI 1997), que desenvolveu a teoria da instrumentalidade, considerando, com seu modelo VIE (Valência, Instrumentalidade e Expectância), que o esforço (força motivacional) que um individuo exerce é função de expectativa de que certos resultados emanarão de seu comportamento e da valência de tais resultados para ele.

1. Se a ação tem alta probabilidade de levar a um resultado (expectância);

2. Se aqueles resultados conduzirão a outros resultados (Instrumentalidade);

3. Se tais resultados têm valor (valência).

Bergamini (1997) enfatiza que cada um desses componentes desempenha importante papel no conjunto da teoria. Em outras palavras, valência diz respeito ao nível de atração pelos fatores do meio ambiente, que nada mais é do que a importância ou desejabilidade que o indivíduo atribui a determinado objetivo a ser colimado. A expectância é aquilo que cada um acredita ser capaz de fazer, aquilo que espera como resultado provável dos seus esforços. Já a ínstrumentalidade diz respeito ao que acontecerá depois de se atingir o resultado; isto é, se esse resultado permitirá a consecução de objetivos posteriores também desejáveis.

Segundo essa teoria, expectância, instrumentalidade e valência representam três componentes essenciais à motivação. O comportamento de todo o trabalhador, qualquer que seja seu status, nível ou qualificação, é função da medida segundo em que ele considera que seu 
trabalho lhe permite atingir seus objetivos pessoais e da medida pela qual ele se estima capaz e se vale a pena fazer esse trabalho de maneira satisfatória. Se um destes três elementos estiver ausente: falta de confiança em si, instrumentalidade discutível, resultados sem relação com as necessidades de cada um, então o delicado processo motivacional se encontra paralisado ou no mínimo desorganizado.

A teoria de Vroom é também chamada de Modelo Contigencial de Motivação pela ênfase dada às diferenças entre as pessoas e os cargos.

Para Lawler (1973 apud BERGAMINI 1997, p.67) a teoria da expectância tenta comprovar que "a satisfação com as recompensas, tais como o pagamento, seja uma função do quanto é recebido, do tanto que se recebe que os outros recebem e da percepção daquilo que deveria ser recebido".

\section{c) Teorias da Motivação Baseadas no Ambiente}

Até então, de acordo com Bowdich (2004), as diversas teorias analisadas procuraram analisar o que energiza e direciona o comportamento humano. Tais modelos trataram a motivação como uma variável predominantemente independente, ou seja, considerando que uma necessidade é a causa de um desejo particular, o qual resulta em certos tipos de comportamento. Diversamente das teorias anteriores, a teoria da motivação baseada no ambiente é apresentada como uma variável interventora e dependente, onde o comportamento pode ser mantido ao longo do tempo. Neste caso, o enfoque é nos antecedentes das variáveis, às quais normalmente é atribuído ao comportamento motivado.

\section{A Teoria da Equidade}

Para Silva (2007), foi J. Stacy Adms, em 1965, quem formulou uma teoria para mostrar como, a partir das relações entre trocas sociais, o comportamento do indivíduo é influenciado. A teoria especifica também os caminhos pelos quais os indivíduos irão responder a tal situação.

Segundo Stoner e Freeman (1999), a teoria da equidade baseia-se na tese de que a avaliação que o indivíduo faz sobre a eqüidade ou a justiça é preponderante para a motivação, o desempenho e a satisfação no trabalho. Segundo eles eqüidade seria uma relação entre a 
contribuição que o indivíduo dá em seu trabalho (como esforço ou a habilidade) e as recompensas que recebe (como o pagamento ou a promoção) comparada com as recompensas que os outros estão recebendo por contribuições semelhantes. Na teoria da eqüidade motivação, desempenho e a satisfação das pessoas dependem da avaliação subjetiva que fazem da relação entre seu quociente esforço/recompensa e o quociente esforço/recompensa de outros em situação semelhantes.

Para Bowditch (2004), se o indivíduo perceber essa relação como desigual, haverá uma tentativa de restaurar a igualdade, seja diminuindo o esforço empenhado (chegando atrasado ou faltando) ou procurando obter recompensas maiores através de outros meios (saindo do emprego ou dirigindo o comportamento para outras atividades).

\section{A Teoria do Condicionamento ou Reforço Operante}

Associado a B.F. Skinner e a outros, a questão da motivação interna é deixada de lado, dando ênfase ao conjunto de fatores externos. Para Stoner e Freeman (1999), das conseqüências dos comportamentos anteriores aos fatos é que irão afetar as ações futuras em um processo cíclico de aprendizado.

Bowditch (2004) lembram que, na visão de Skinner o comportamento humano é determinado e mantido pelo ambiente da pessoa. À medida que indivíduo explora e reage a ele, certos comportamentos serão reforçados e subseqüentemente repetidos. Dessa forma, a motivação será em função das conseqüências daquele comportamento. Assim, caso seja recompensado para agir de certo modo, fará uma ligação entre comportamento apropriado e recompensa, e continuará a apresentar tal comportamento.

Para esses autores, a teoria do reforço sugere que, se alguém quiser manter um certo comportamento no trabalho, precisará manipular as conseqüências daquele comportamento. Seja por meios de recompensas (reforço positivo) ou punições (reforço negativo). Eles ressaltam que o condicionamento operante é útil para explicar a relação entre satisfação e desempenho. Pois, originalmente se pensava que a satisfação intensa no trabalho levava o bom desempenho. Hoje, entretanto, é de consenso geral que isso funciona ao inverso, ou seja, que bom desempenho, quando suficientemente recompensado (reforçado), é que leva à satisfação. 
Bergamini (1997) enfatiza que as teorias comportamentais não levaram em conta que as pessoas são diferentes entre si e em razão disso não reagirão da mesma forma quando submetidos ao mesmo tipo de reforço. Que ao ignorar individualidade do ser humano, negam que ele tenha opções pessoais, podendo não só mudar, por iniciativa própria, de trabalho, como também de emprego.

A crítica que se concentra em preocupações de ordem ética quanto a manipulação de trabalhadores e modificação de comportamento. Segundo Bowdich e Buono (2004), outros argumentam que a tentativa de moldar o comportamento funcione bem com os cães e outros animais, porém é menos eficaz com as pessoas, seres complexos com necessidades e motivos de facetas múltiplas.

\section{2 - A Satisfação no Trabalho}

Dailey (1995) declara que satisfação no trabalho é uma atitude chave do empregado e está relacionada, sistematicamente, com as necessidades dos empregados e a produtividade organizacional. Ela relaciona-se com a rotatividade no emprego, absenteísmo, saúde física e emocional do trabalhador, desempenho do trabalhador e percepções de justiça dos sistemas de recompensa oferecidos pela organização.

Na opinião de muitos autores, a satisfação no trabalho é um dos temas mais conhecidos e discutidos na literatura de comportamento organizacional. Segundo Siqueira e Gomide Júnior (2004), nas décadas de 1960 e 70, surgiram novas correntes de pesquisa que tentavam explicar os fatores capazes de influenciar resultados organizacionais advindos da força de trabalho.

Os temas “satisfação” e “envolvimento” no trabalho, afirmam Siqueira e Gomide Júnior, dominaram as pesquisas da época que buscavam identificar os fatores possíveis de interferência nos níveis de produtividade das organizações. Esses estudos estavam diretamente relacionados com a compreensão do comportamento humano no trabalho.

Esses autores esclarecem ainda que desde as décadas iniciais do século passado, muitos estudos têm sido conduzidos com o objetivo de desvendar as dimensões, as possíveis causas e conseqüências que estão relacionadas a um sentimento que emerge quando o homem se relaciona com o seu trabalho. Esse sentimento é conhecido por "satisfação no trabalho” e, segundo os 
autores, é a variável de natureza afetiva que maior atração tem exercido sobre os estudiosos da Psicologia Organizacional e do Trabalho.

Indivíduos satisfeitos no trabalho podem apresentar resultados organizacionais importantes, como por exemplo, alta produtividade, alto desempenho, baixo absenteísmo e baixa rotatividade, lembram Siqueira e Gomide Júnior.

Locke (1976 apud SIQUEIRA; GOMIDE JÚNIOR, 2004) define satisfação no trabalho como um estado emocional positivo ou de prazer, resultante de um trabalho ou de experiências de trabalho.

Na concepção de Robbins (1999), satisfação no trabalho é uma atitude geral do indivíduo em relação ao seu emprego. Para ele, as atitudes são constatações avaliadoras, favoráveis ou não, em relação às pessoas, objetos ou eventos, ou seja, elas refletem como alguém se sente em relação a algo.

Uma variação da proposta de Robbins é feita por Spector (2002). Para o autor, satisfação é uma variável de atitude que reflete como uma pessoa se sente em relação ao trabalho de forma geral e em seus vários aspectos. É o quanto as pessoas gostam de seu trabalho.

De acordo com Siqueira e Gomide Júnior (2004) todo o conjunto de argumentos para justificar a relevância de satisfação no trabalho não está necessariamente preocupado com a efetividade e a competitividade organizacionais. Na análise desses autores, a preocupação está ligada a uma concepção social segundo a qual trabalhador satisfeito com seu trabalho pode se tornar uma pessoa com mais possibilidades de ser um cidadão integrado à sociedade, à sua família e apresentar melhores índices de bem-estar físico e mental.

Estudos conduzidos por diversos autores têm apontado que a satisfação no trabalho pode estar correlacionada com variáveis integrantes do bem-estar, como satisfação geral com a vida, estado de ânimo, otimismo e auto-estima.

\subsection{1 - Os Fatores da Satisfação no Trabalho}

A literatura é unânime em afirmar que a satisfação no trabalho não é formada por um único fator, mas por um conjunto de fatores ou facetas. Essas facetas, segundo explica Dailey (1995), sofrem variações em razão das percepções que os empregados têm sobre elementos importantes no seu ambiente de trabalho como recompensas, estilos de liderança, tipo de 
atividades desenvolvidas, entre outros. Para Dailey, cada faceta representa uma predisposição que o indivíduo tem para responder às pessoas, objetos ou instituições de uma forma positiva ou negativa. Essas facetas da satisfação no trabalho seriam atitudes focadas em:

- Satisfação com o próprio trabalho.

- Satisfação com a remuneração.

- Satisfação com os colegas de trabalho.

- Satisfação com o supervisor.

- Satisfação com as promoções.

Segundo Dailey (1995), para os empregados, a importância de cada uma dessas facetas se altera de acordo com a rotina diária de trabalho. Dessa forma, um empregado pode estar muito satisfeito com uma determinada faceta, mas insatisfeito com outra.

Siqueira e Gomide Júnior (2004) reconhecem o caráter multifacetado do conceito de satisfação no trabalho, apontando em um diagrama as mesmas cinco facetas citadas anteriormente:

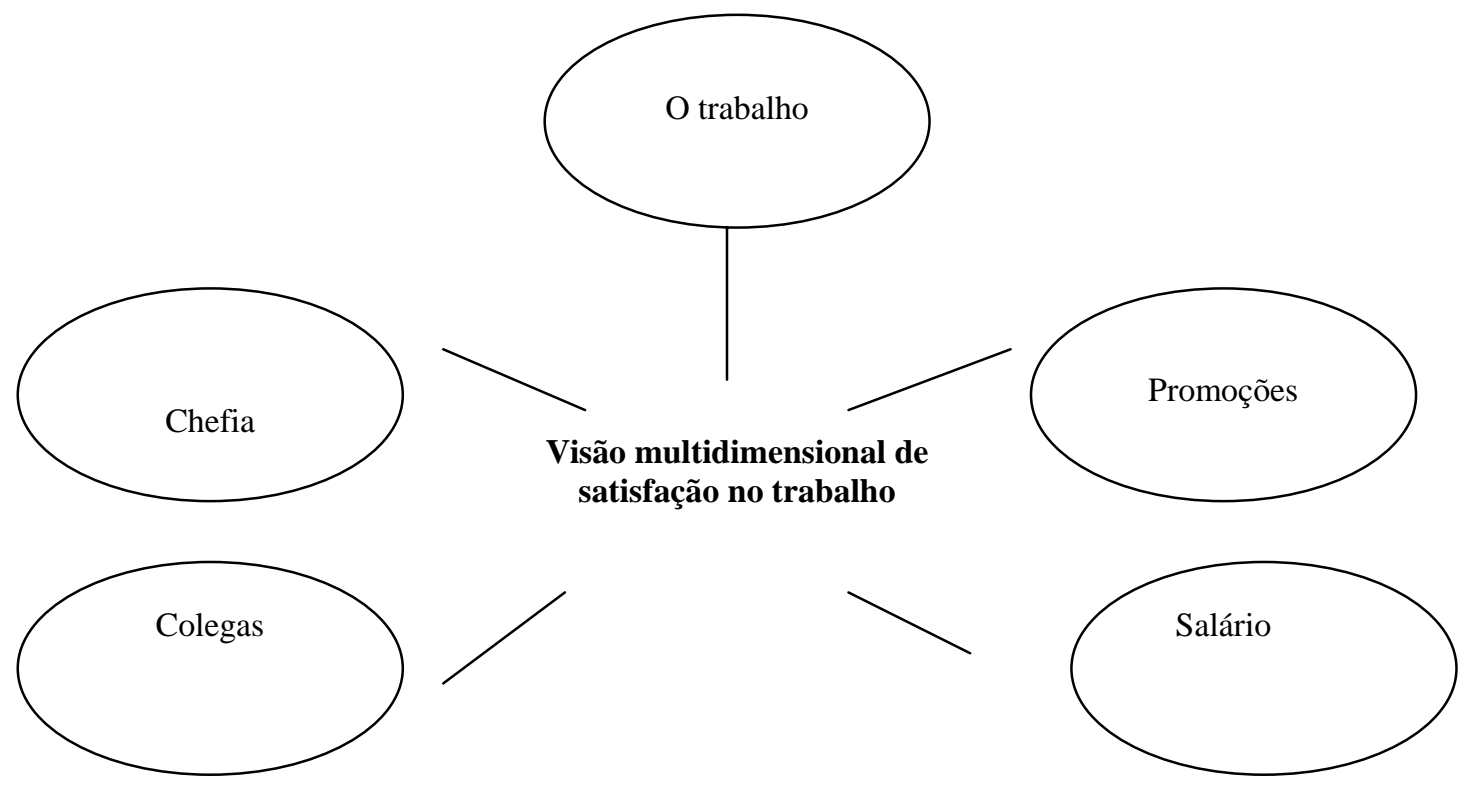

Figura 3 - Cinco Fatores de Satisfação no Trabalho

Fonte: Siqueira e Gomide Júnior (2004) 
Uma análise da literatura mostra que, muitas vezes, há certa confusão entre os conceitos de motivação e satisfação no trabalho. Pérez-Ramos (1980 apud MARTINEZ; PARAGUAY, 2003) salienta que essa confusão entre os dois termos tem provocado falhas na formulação de hipóteses e na seleção de instrumentos de pesquisas, especialmente naquelas destinadas a correlacionar satisfação no trabalho com produtividade.

Para Steuer (1989 apud MARTINEZ; PARAGUAY, 2003), a diferença entre motivação e satisfação é que a primeira manifesta a tensão gerada por uma necessidade e a segunda expressa a sensação de atendimento dessa necessidade.

O presente trabalho trata sobre a satisfação no trabalho. O próximo capítulo descreverá os procedimentos metodológicos adotados na realização da pesquisa empírica. 


\section{Capítulo 2 - Aspectos Metodológicos da Pesquisa}

Este Capítulo descreve os procedimentos metodológicos aplicados à realização da pesquisa e está dividido em seis seções: 1) tipo de pesquisa; 2) contexto da pesquisa; 3) participantes da pesquisa; 4) instrumento da pesquisa; 5) procedimentos de coleta de dados; 6) procedimentos de análise de dados.

\section{1 - Tipo de Pesquisa}

A literatura da área de Metodologia Científica apresenta várias nomenclaturas para explicar os tipos de pesquisa que podem ser realizados por um pesquisador. Segundo a classificação de Martins (2003), o presente estudo pode ser descrito como tendo, pelo menos, três grandes características:

- Empírico-analítico - trata-se de um estudo que apresenta a utilização de técnicas de coleta, tratamento e análise de dados essencialmente quantitativas.

- De campo - caracteriza-se pela coleta direta de informações no local em que acontecem os fenômenos.

- Survey (enquete) - foi feito um levantamento junto às fontes primárias, por meio de aplicação de questionários para grande quantidade de pessoas.

\section{2 - Contexto da Pesquisa}

A pesquisa foi realizada no Superior Tribunal de Justiça (STJ), instituição Pública de Direito Público, com sede na Capital Federal, criado pela Constituição de 1988. Segundo dados da Instituição, até setembro de 2008 o quadro funcional do STJ contava com 2.625 cargos efetivos, dos quais 988 são de nível superior, 1.636 de nível intermediário e 1 de nível auxiliar, distribuídos nas áreas judiciária, administrativa e gabinetes de Ministros. 


\section{3 - Participantes da Pesquisa}

A pesquisa foi conduzida em um segmento específico da população organizacional - os servidores ocupantes da área da secretaria de segurança. Os integrantes dessa unidade somam um total de cento e quarenta e três servidores, sendo que apenas noventa e quatro participaram do estudo respondendo ao questionário. Esses participantes efetivos da pesquisa apresentaram o seguinte perfil demográfico:

\subsection{1 - Gênero}

Tabela 1 - Gênero dos Participantes da Pesquisa

\begin{tabular}{l|c|c}
\multicolumn{1}{c|}{ Gênero } & f & $\mathbf{\%}$ \\
\hline Masculino & 68 & 72,3 \\
\hline Feminino & 26 & 27,7 \\
\hline Total & $\mathbf{9 4}$ & $\mathbf{1 0 0 , 0}$ \\
\hline
\end{tabular}

Os dados da Tabela 1 mostram que a maior parte dos respondentes (72,3\%) pertence ao sexo masculino, contra $27,7 \%$ de respondentes do sexo feminino. É possível que esse resultado reflita o tipo de atuação do segmento organizacional escolhido para a pesquisa - área de segurança do Tribunal - onde, tradicionalmente, observa-se a presença mais acentuada de pessoas do sexo masculino.

\subsection{2 - Faixa Etária}

A Tabela 2, apresentada a seguir, ilustra a distribuição dos participantes da pesquisa em função da faixa etária: 
Tabela 2 - Faixa Etária dos Participantes da Pesquisa

\begin{tabular}{l|c|c}
\multicolumn{1}{c|}{ Faixa Etária } & $\mathbf{f}$ & \% \\
\hline Até 20 anos & 2 & 2,1 \\
\hline 21 a 30 anos & 12 & 12,8 \\
\hline 31 a 40 anos & 22 & 23,4 \\
\hline 41 a 50 anos & 49 & 52,1 \\
\hline Mais de 50 anos & 8 & 8,5 \\
\hline Dado Ausente & 1 & 1,1 \\
\hline \multicolumn{1}{c|}{ Total } & $\mathbf{9 4}$ & $\mathbf{1 0 0 , 0}$ \\
\hline
\end{tabular}

Observa-se na Tabela 2 que mais da metade dos participantes da pesquisa (52,1\%) pertence à faixa etária entre 41 e 50 anos. O menor percentual (2,1\%) foi de respondentes com até 20 anos de idade.

\subsection{3 - Escolaridade}

Tabela 3 - Escolaridade dos Participantes da Pesquisa

\begin{tabular}{l|c|c}
\multicolumn{1}{c|}{ Escolaridade } & f & \% \\
\hline Fundamental Completo & 3 & 3,2 \\
\hline Médio Incompleto & 4 & 4,3 \\
\hline Médio Completo & 41 & 43,6 \\
\hline Superior Incompleto & 17 & 18,0 \\
\hline Superior Completo & 23 & 24,5 \\
\hline Especialização Incompleta & 1 & 1,1 \\
\hline Especialização Completa & 5 & 5,3 \\
\hline \multicolumn{1}{c|}{ Total } & $\mathbf{9 4}$ & $\mathbf{1 0 0 , 0}$ \\
\hline
\end{tabular}

Os dados da Tabela 2 mostram que o maior percentual (43,6\%) corresponde aos participantes que relataram possuir nível médio completo. O segundo maior percentual observado é de pessoas com curso superior (30,9\%). Esse percentual é obtido somando-se os respondentes com curso superior completo e pós-graduação completa ou incompleta. 


\subsection{4 - Estado Civil}

Tabela 4 - Estado Civil dos Participantes da Pesquisa

\begin{tabular}{l|c|c}
\multicolumn{1}{c|}{ Estado Civil } & f & \% \\
Casado & 48 & 51,1 \\
\hline Solteiro & 24 & 25,5 \\
\hline Viúvo & 2 & 2,1 \\
\hline Separado & 8 & 8,5 \\
\hline Divorciado & 10 & 10,6 \\
\hline Outro & 1 & 1,1 \\
\hline Dado Ausente & 1 & 1,1 \\
\hline
\end{tabular}

Mais da metade dos respondentes $(51,1 \%)$ é casada, conforme aponta a Tabela 4 . O segundo maior percentual (25,5\%) é de pessoas solteiras.

\subsection{5 - Tempo de Serviço}

Tabela 5 - Tempo de Serviço no Tribunal dos Participantes da Pesquisa

\begin{tabular}{|c|c|c|}
\hline Tempo de Serviço no Tribunal & f & $\%$ \\
\hline Menos de 1 ano & 5 & 5,3 \\
\hline 1 a 5 anos & 12 & 12,8 \\
\hline 6 a 10 anos & 12 & 12,8 \\
\hline 11 a 15 anos & 22 & 23,4 \\
\hline 16 a 20 anos & 33 & 35,1 \\
\hline Mais de 20 anos & 10 & 10,6 \\
\hline Total & 94 & 100,0 \\
\hline
\end{tabular}

Os dados da Tabela 5 mostram que o maior percentual de respondentes (35,1\%) possui entre 16 e 20 anos de serviço no STJ. Apenas 10,6\% relataram ter mais de 20 anos de tempo de serviço na Instituição. 


\subsection{6 - Vínculo Empregatício}

Tabela 6 - Tipo de Vínculo Empregatício

\begin{tabular}{l|c|c}
\multicolumn{1}{c|}{ Vínculo Empregatício } & f & \% \\
\hline Analista Judiciário & 2 & 2,1 \\
\hline Técnico Judiciário & 71 & 75,5 \\
\hline Requisitado & 2 & 2,1 \\
\hline Terceirizado & 15 & 16,0 \\
\hline Em exercício provisório & 1 & 1,1 \\
\hline Dado Ausente & 3 & 3,2 \\
\hline \multicolumn{1}{c|}{ Total } & $\mathbf{9 4}$ & $\mathbf{1 0 0 , 0}$ \\
\hline
\end{tabular}

A maior parte dos respondentes (75,5\%) são servidores do quadro do Tribunal, ocupantes do cargo de Técnico Judiciário. O segundo maior percentual (16,0\%) refere-se a respondentes que prestam serviço terceirizado.

\subsection{7 - Exercício de Cargo de Chefia}

Tabela 7 - Exercício de Cargo de Chefia

\begin{tabular}{|c|c|c|}
\hline Cargo de Chefia & f & $\%$ \\
\hline Sim & 26 & 27,7 \\
\hline Não & 66 & 70,2 \\
\hline Dado Ausente & 2 & 2,1 \\
\hline Total & 94 & 100,0 \\
\hline
\end{tabular}

Dos 94 sujeitos que responderam ao questionário de pesquisa, apenas 27,7\% relataram exercer ou já ter exercido cargo de chefia.

\section{5 -Instrumento da Pesquisa}

Para se mensurar a satisfação no trabalho do servidor judiciário, utilizou-se a Escala de Satisfação no Trabalho construída e validada por Siqueira (1995). O instrumento, em sua versão reduzida, é formado por 15 itens a serem respondidos em uma escala do tipo "Lickert", de 7 
pontos, variando de 1 = totalmente insatisfeito até 7 = totalmente satisfeito. Cópia do instrumento utilizado na pesquisa encontra-se no Anexo “A” desta Monografia.

A validação da Escala de Satisfação no Trabalho, feita por Siqueira (1995), mostrou que os 15 itens agruparam-se em cinco fatores, todos com bons níveis de confiabilidade (Alpha de Cronbach), conforme descrito a seguir:

- Fator 1: Colegas de trabalho $(\alpha=0,81)$

- Fator 2: Salário $(\alpha=0,90)$

- Fator 3: Chefia $(\alpha=0,89)$

- Fator 4: Natureza do Trabalho $(\alpha=0,77)$

- Fator 5: Promoções $(\alpha=0,81)$

O Quadro 5 mostra a descrição dos itens que compõem a Escala de Satisfação no trabalho, agrupados em seus respectivos fatores:

\begin{tabular}{|c|c|}
\hline \multirow[b]{2}{*}{ Fator } & Descrição Abreviada do Item \\
\hline & No meu trabalho sinto-me.... \\
\hline \multirow{3}{*}{ F1 - Colegas de Trabalho } & Com o espírito de colaboração dos meus colegas de trabalho \\
\hline & Com o tipo de amizade que meus colegas demonstram por mim \\
\hline & Com a confiança que eu posso ter em meus colegas de trabalho \\
\hline \multirow{3}{*}{ F2 - Salário } & Com o meu salário comparado com o quanto eu trabalho \\
\hline & Com o meu salário comparado com a minha capacidade profissional \\
\hline & Com o meu salário comparado com meus esforços no trabalho \\
\hline \multirow{3}{*}{ F3 - Chefia } & Com o entendimento entre eu e meu chefe \\
\hline & Com a maneira como meu chefe trata-me \\
\hline & Com a capacidade profissional do meu chefe \\
\hline \multirow{3}{*}{ F4 - Natureza do Trabalho } & Com o grau de interesse que minhas tarefas me despertam \\
\hline & Com a capacidade de o meu trabalho absorver-me \\
\hline & Com a variedade de tarefas que realizo \\
\hline \multirow{2}{*}{ F5 - Promoções } & Com o número de vezes que já fui promovido nesta empresa \\
\hline & $\begin{array}{l}\text { Com a maneira como esta empresa realiza promoções de pessoal } \\
\text { Com as oportunidades de ser promovido nesta empresa }\end{array}$ \\
\hline
\end{tabular}

Quadro 5 - Descrição dos Itens e Fatores da Escala de Satisfação no Trabalho 
Aos 15 itens que formavam o instrumento foram acrescidas mais oito questões com o objetivo de se traçar o perfil demográfico dos participantes da pesquisa. Essas questões referiamse às seguintes variáveis: a) gênero; b) escolaridade; c) faixa etária; d) estado civil; e) tempo de serviço no Tribunal; f) tipo de vínculo; g) exercício de cargo de chefia.

\section{5 - Procedimentos de Coleta dos Dados}

Os questionários de pesquisa foram impressos e distribuídos pessoalmente pelo pesquisador, com a informação de que os dados seriam tratados de forma sigilosa e não seriam identificados os respondentes.

Os questionários foram recolhidos no dia seguinte, pelo próprio pesquisador, que utilizou um envelope grande para assegurar que os respondentes tivessem sua identidade mantida no anonimato.

\section{6 - Análise dos Dados}

A análise dos dados seguiu as seguintes etapas:

- Verificação dos questionários devolvidos para identificar aqueles que não poderiam ser aproveitados, como por exemplo, os que tivessem mais de $5 \%$ de respostas ausentes.

- Numeração dos questionários válidos.

- Preparação do banco de dados no Statistical Package for Social Sciences (SPSS).

- Digitação dos dados dos questionários.

- Realização de estatísticas descritivas (freqüência, média e desvio padrão). 


\section{Capítulo 3 - Apresentação e Discussão dos Resultados}

O presente Capítulo trata dos resultados encontrados com a realização da pesquisa empírica que teve por objetivo geral investigar os fatores que promovem satisfação e insatisfação no trabalho do servidor judiciário. Os seguintes objetivos específicos foram estabelecidos:

- Revisar a literatura sobre Satisfação no Trabalho.

- Verificar, na percepção dos servidores do judiciário, os fatores responsáveis pela satisfação e insatisfação no trabalho.

- Fornecer subsídios para melhoria da política de pessoal da Instituição pesquisada.

A revisão da literatura - primeiro objetivo específico da pesquisa - foi feita no Capítulo 1 do trabalho. Os resultados dos demais objetivos serão apresentados e discutidos a seguir.

\section{1 - A Satisfação no Trabalho do Servidor do Poder Judiciário}

Para mensurar a percepção sobre a satisfação no trabalho do servidor do Poder Judiciário, foi utilizado o instrumento construído e validado por Siqueira (1995), composto por 15 itens distribuídos em cinco fatores denominados: Colegas de Trabalho; Salário; Chefia; Natureza do Trabalho, Promoções. A Tabela 8 apresenta a média e o desvio padrão encontrados para cada um dos cinco fatores do instrumento:

Tabela 8- Média e Desvio Padrão dos Fatores do Instrumento de Satisfação no Trabalho

\begin{tabular}{l|c|c}
\multicolumn{1}{c|}{ Fator } & Média & Desvio Padrão \\
\hline F1 = Colegas de Trabalho & 5,55 & 0,84 \\
\hline F2 = Salário & 5,52 & 1,27 \\
\hline F3 = Chefia & 5,81 & 0,92 \\
\hline F4 = Natureza do Trabalho & 4,84 & 1,08 \\
\hline F5 = Promoções & 3,27 & 1,55 \\
\hline
\end{tabular}


Os dados da Tabela 8 mostram que, de todos as facetas que contribuem para a satisfação no trabalho, mensurados pelo instrumento de Siqueira (1995), os servidores do STJ que participaram da pesquisa reportaram estar mais satisfeitos com o tipo de chefia que possuem (média de 5,81) e menos satisfeitos com a política de promoções (média de 3,27). Uma análise mais detalhada do resultado de cada um dos fatores é apresentada a seguir:

- Colegas de Trabalho (Fator 1) - Observa-se que a média desse Fator foi 5,55, ficando entre os pontos 5 "satisfeito" e 6 "muito satisfeito" da escala do instrumento. Isso significa que, na percepção dos servidores que participaram da pesquisa, há um bom nível de satisfação com relação aos colegas de trabalho. O desvio padrão baixo $(0,84)$, mostra que houve concordância entre os respondentes com relação a esse quesito.

- Salário (Fator 2) - A média das respostas dadas pelos participantes aos itens que formavam esse fator foi de 5,52. Como aconteceu com o Fator anterior, essa média também se posicionou entre os pontos 5 (satisfeito) e 6 (muito satisfeito), sinalizando que os participantes da pesquisa reportaram um bom nível de satisfação com o salário que recebem. Ressalta-se, contudo, um desvio padrão alto $(1,27)$, o que demonstra que houve discordância entre os participantes da pesquisa com relação às afirmações feitas nesse quesito.

- Chefia (Fator 3) - A média das respostas a esse Fator foi de 5,81, média mais alta dos cinco fatores, aproximando mais do ponto 6 (muito satisfeito). Esse resultado sinaliza que os empregados demonstram estar satisfeitos com suas respectivas chefias. O desvio padrão baixo $(0,92)$ reflete boa concordância entre os participantes com relação aos itens que formavam o Fator.

- Natureza do Trabalho (Fator 4) - Nesse Fator a média foi de 4,84, ficando entre os pontos 4 (indiferente) e 5 (satisfeito), aproximando mais do ponto 5 da escala, ou seja, chegando próximo a um nível de satisfação com a natureza do trabalho que realizam. 
- Promoções (Fator 5) - O resultado nesse Fator demonstra que a média ficou entre 3 (insatisfeito) e 4 (indiferente), indicando que os empregados demonstram insatisfação ou indiferença com relação às oportunidades de promoções.

Para se compreender melhor as respostas dadas pelos participantes da pesquisa aos itens que formam o instrumento de Satisfação no Trabalho, serão apresentados, a seguir, as médias e os desvios padrões dos itens de cada um dos cinco fatores.

Tabela 9 - Média e Desvio Padrão dos Itens do Instrumento Satisfação no Trabalho

\begin{tabular}{|c|c|c|c|}
\hline \multirow[b]{2}{*}{ Fator } & Descrição Abreviada do Item & \multirow[b]{2}{*}{ Média } & \multirow{2}{*}{$\begin{array}{l}\text { Desvio } \\
\text { Padrão }\end{array}$} \\
\hline & No meu trabalho atual sinto-me.... & & \\
\hline \multirow{3}{*}{$\begin{array}{c}\text { (1) } \\
\text { Colegas de } \\
\text { Trabalho }\end{array}$} & Com o espírito de colaboração dos meus colegas de trabalho & 5,37 & 1,21 \\
\hline & Com o tipo de amizade que meus colegas demonstram por mim & 5,80 & 1,00 \\
\hline & Com a confiança que eu posso ter em meus colegas de trabalho & 5,52 & 1,12 \\
\hline \multirow{3}{*}{$\begin{array}{c}\text { (2) } \\
\text { Salário }\end{array}$} & Com o meu salário comparado com o quanto eu trabalho & 5,55 & 1,66 \\
\hline & Com o meu salário comparado com a minha capacidade profissional & 5,55 & 1,47 \\
\hline & Com o meu salário comparado com meus esforços no trabalho & 5,43 & 1,26 \\
\hline \multirow{3}{*}{$\begin{array}{c}\text { (3) } \\
\text { Chefia }\end{array}$} & Com o entendimento entre eu e meu chefe & 5,84 & 1,00 \\
\hline & Com a maneira como meu chefe trata-me & 5,73 & 1,20 \\
\hline & Com a capacidade profissional do meu chefe & 5,83 & 1,00 \\
\hline \multirow{3}{*}{$\begin{array}{c}(4) \\
\text { Natureza do } \\
\text { Trabalho }\end{array}$} & Com o grau de interesse que minhas tarefas me despertam & 5,64 & 1,34 \\
\hline & Com a capacidade de o meu trabalho absorver-me & 4,07 & 1,80 \\
\hline & Com a variedade de tarefas que realizo & 4,82 & 1,59 \\
\hline \multirow{3}{*}{$\begin{array}{c}\text { (5) } \\
\text { Promoções }\end{array}$} & Com o número de vezes que já fui promovido nesta empresa & 3,70 & 1,93 \\
\hline & Com a maneira como esta empresa realiza promoções de pessoal & 3,02 & 1,80 \\
\hline & Com as oportunidades de ser promovido nesta empresa & 3,06 & 1,82 \\
\hline
\end{tabular}

No Fator "Colegas de Trabalho", destaca-se que a média mais alta, 5,80, foi para o item “com o tipo de amizade que meus colegas demonstram por mim”. Esse resultado sinaliza que, na percepção dos participantes da pesquisa, eles estão próximos do ponto 6 da escala, ou seja, “muito satisfeito” com esse quesito. Porém, ele mostra um nível um pouco menor de satisfação 
com os itens que envolvem trabalho em equipe e confiança no colega de trabalho. O desvio padrão no valor de 1,00 ainda retrata concordância entre os respondentes.

No Fator "Salário”, dois itens ficaram com a média mais alta, 5,55: “com o meu salário comparado com o quanto eu trabalho" e "com o meu salário comparado com a minha capacidade profissional“. Esse valor, que se posiciona entre os pontos 5 "satisfeito” e 6 "muito satisfeito" sinaliza que, aparentemente, os servidores do Tribunal que participaram da pesquisa demonstram um bom nível de satisfação com o salário que recebem. Entretanto, o desvio padrão muito alto, aponta que houve pouca concordância entre os participantes com respeito a esses itens.

O Fator 3, "Chefia”, recebeu a média mais alta no item "com o entendimento entre eu e meu chefe”, demonstrando um bom nível de satisfação, 5,84. O resultado sinaliza que, nesse quesito, os chefes, na unidade de segurança, exercem uma boa liderança dentre os funcionários. O desvio padrão encontrado mostra boa concordância entre os respondentes com relação ao item.

Com relação ao Fator 4, "Natureza do Trabalho”, observa-se que o item “com o grau de interesse que minhas tarefas me despertam” recebeu a média mais alta, 5,64. Esse é um resultado que se mostra positivo para o setor, pois aponta que os empregados consideram interessantes as tarefas que realizam. Entretanto, nem todos os participantes concordaram com a afirmação, conforme revela o valor alto apresentado pelo desvio padrão.

No Fator 5, "Promoções”, o item “com o número de vezes que já fui promovido nesta empresa” recebeu a média mais alta, 3,70. Esse valor fica entre os pontos 3 (insatisfeito) e 4 (indiferente), sinalizando que há espaço para melhoria na política de promoção interna de pessoal no setor de segurança do Tribunal. O desvio padrão muito alto demonstra pouca concordância entre os respondentes com relação às respostas dadas ao item.

\section{2 - Subsídios para a Política de Pessoal do STJ}

Conforme mencionado no Capítulo 2, a pesquisa realizada neste trabalho envolveu apenas um segmento específico do STJ - os servidores ocupantes da área da secretaria de segurança. Os resultados encontrados permitem visualizar um quadro bastante favorável de satisfação no trabalho entre os servidores que atuam nessa área do Tribunal.

De uma maneira geral, observou-se que os servidores demonstram estar satisfeitos com os colegas de trabalho, o salário, as chefias a quem estão subordinados e a natureza do trabalho que 
executam. A faceta que os servidores demonstraram estar menos satisfeitos diz respeito às promoções recebidas. 


\section{CONCLUSÃO}

Esta Monografia foi elaborada para atender a um dos requisitos à obtenção do grau de Especialista em Gestão Judiciária e abordou o seguinte problema de pesquisa: “Quais são os determinantes da satisfação no trabalho do servidor do judiciário?”.

A revisão de literatura mostrou que Satisfação no Trabalho é um conceito multidimensional e multifacetado. O empregado pode estar satisfeito com o seu salário, mas pode estar insatisfeito com a sua chefia ou com os seus colegas de trabalho, por exemplo.

Pesquisa realizada por Sena e Pieruccetti (2005) em uma empresa de prestação de serviços, encontrou que os empregados demonstraram ter um nível maior de satisfação com relação às suas chefias, mas estavam insatisfeitos com relação ao salário e às promoções.

Santos (2008), utilizando o instrumento de Siqueira (1999) para mensurar a satisfação no trabalho de empregados de uma empresa do comércio varejista encontrou que dos cinco fatores pesquisados somente um - "Chefia” - recebeu uma média boa, ficando entre os pontos 5 (satisfeito) e 6 (muito satisfeito). Os demais fatores - colegas de trabalho, salário, natureza do trabalho e promoções - receberam médias mais baixas.

No caso específico da pesquisa conduzida neste trabalho, feita com servidores que atuam na área de segurança do Superior Tribunal da Justiça (STJ), os resultados apontaram que os participantes da pesquisa demonstraram um bom nível de satisfação com vários aspectos importantes tais como: os colegas de trabalho, o salário, suas chefias e a natureza do trabalho que realizam. Apenas no Fator "Promoções”, eles se mostraram menos satisfeitos. Dentre os cinco fatores que compunham o instrumento utilizado para mensurar a satisfação no trabalho, “Promoções” foi o que recebeu a média mais baixa.

Uma comparação entre a pesquisa realizada no STJ e as realizadas na iniciativa privada por Sena e Pieruccetti (2005) e Santos (2008) aponta que os servidores do Tribunal mostraram estar satisfeitos com um número maior de fatores. Esse resultado parece condizente com a imagem que o poder judiciário desfruta na sociedade - uma instituição que oferece boas condições de trabalho.

Embora os resultados encontrados nesta pesquisa não possam ser generalizados, em função do número pequeno de participantes, espera-se que ela possa servir de incentivo para que o STJ investigue o nível de satisfação dos servidores de outras áreas da Instituição. Saber que 
aspectos favorecem a satisfação do servidor pode fornecer importantes subsídios para a área de gestão de pessoas. Os resultados de uma pesquisa de satisfação no trabalho poderiam ser cruzados com outros indicadores, como por exemplo, os resultados de pesquisa de clima organizacional, fornecendo uma visão mais detalhada do ambiente de trabalho do Superior Tribunal de Justiça. 


\section{REFERÊNCIAS}

BERGAMINI, C. W. Motivação nas organizações. 4. ed. São Paulo: Atlas, 1997.

Motivação: mitos, crenças e mal-entendidos. Revista de Administração de Empresas RAE. São Paulo, n.1, p. 6-17 Abr/Jun. 1990.

A difícil administração das motivações. Revista de Administração de Empresas RAE. São Paulo, v. 38 , n.1, p. 6-17 Jan/Mar. 1998.

BORGES, L.O.; ALVES FILHO, A. A mensuração da motivação e do significado do trabalho. Estudos de Psicologia, 177-194, 2001.

BOWDITCH, J. L. Motivação. In: Elementos de comportamento organizacional. Trad. José Henrique Lamendorf.. São Paulo. Pioneira Thomson Learning. 2004. cap. 3.

DAILEY, R. Organisational Behaviour. Edinburgh Business School MBA Series. Heriot-Watt University. Edinburgh: Pitiman Publishing, 1995.

MARTINEZ, M.C.; PARAGUAY, A.I.B.B. Satisfação e saúde no trabalho - aspectos conceituais e metodológicos. Caderno de Psicologia Social do Trabalho, v. 6, n.1 São Paulo, dez. 2003.

LOBOS, J. Teorias sobre motivação no trabalho. Revista de Adminisração de Empresas RAE. Rio de Janeiro: Fundação Getúlio Vargas, v. 15 n.2 mar/abr, p. 17 - 25, 1975.

LOPES, T. V. M. Motivação no trabalho. Rio de Janeiro: Fundação Getúlio Vargas, 1980.

ROBBINS, S. P. Comportamento Organizacional. Rio de Janeiro: LTC, 2001.

. Conceitos básicos de motivação. In:

Comportamento organizacional. Trad.

Reynaldo Marcondes. 9. ed. São Paulo: Prentice Hall, 2002. cap. 6.

SANTOS, F.C.F. A satisfação no trabalho e o comprometimento organizacional na área de comércio varejista. 2008. Monografia (Especialização em Gestão de Pessoas). Programa de PósGraduação em Administração, Universidade de Brasília, Brasília.

SENA, A.S.; PIERUCCETTI, F.M.G. Satisfação no trabalho em uma empresa de terceirização de serviços. 2005. Monografia (Especialização em Gestão de Recursos Humanos). Universidade Católica de Brasília.

SILVA, W. R. da; RODRIGUES, C. M. C. Motivação nas organizações. São Paulo: Atlas, 2007. 
SIQUEIRA, M.M.M. Antecedentes de Comportamentos de Cidadania Organizacional: a análise de um modelo pós-cognitivo. 1995. Tese (Doutorado em Psicologia) - Instituto de Psicologia, Universidade de Brasília, Brasília.

SIQUEIRA, M.M.M.; GOMIDE JÚNIOR, S. Vínculos do Indivíduo com o Trabalho e com a Organização. In: ZANELLI, J.C.; BORGES-ANDRADE, J.E.; BASTOS, A.V.B. (Orgs.). Psicologia, Organizações e Trabalho no Brasil. Porto Alegre: Artmed, 2004.

SPECTOR, P. E. Psicologia nas Organizações. São Paulo: Saraiva, 2002.

STONER, J.; FREEMAN, R. E. Motivação, Desempenho e Satisfação no Trabalho. In:

Administração. 5. ed. Rio de janeiro: Prentice Hall do Brasil, 1999. cap. 15.

TAMAYO, Á; Paschoal T. A relação da Motivação para o trabalho com as metas do trabalhador. RAC, v.7, n. 4, p. 33-34, out./dez. 2003.

VERGARA, S. C. Começando a definir a metodologia. In: - Projetos e relatórios de pesquisa em administração. 3. ed. São Paulo: Atlas, 2000. cap.4. 


\section{Anexo “A” \\ PESQUISA SOBRE SATISFAÇÃO NO TRABALHO}

\section{Caro (a) Colega,}

Esta pesquisa é para uma monografia de especialização em Gestão Judiciária, realizada na Universidade de Brasília. Conto com sua valiosa contribuição para respondê-la.

Você não será identificado. Suas respostas serão analisadas de forma conjunta, garantindo o anonimato.

Agradeço antecipadamente sua colaboração. Maurício César - Mauricio.matos@sti.jus.br Ramal: 7048

\section{Instruções de Preenchimento:}

- As frases abaixo falam a respeito de alguns aspectos do seu trabalho atual. Gostaríamos que você indicasse o quanto se sente satisfeito ou insatisfeito com cada um deles, marcando um " $X$ " na coluna referente ao número que melhor representa a sua resposta.

- POR FAVOR, não deixe nenhuma questão sem resposta. Não há resposta certa ou errada.

\begin{tabular}{|c|c|c|}
\hline $1=$ totalmente insatisfeitc & & $7=$ totalmente satisfeito \\
\hline $2=$ muito insatisfeito & & $6=$ muito satisfeito \\
\hline $3=$ insatisfeito & & $5=$ satisfeito \\
\hline
\end{tabular}

No meu trabalho atual sinto-me...

\section{Com o espírito de colaboração dos meus colegas de trabalho}

Com o número de vezes que já fui promovido nesta empresa.

Com o meu salário comparado com o quanto eu trabalho.

Com o tipo de amizade que os meus colegas demonstram por mim.

Com o grau de interesse que minhas tarefas me despertam.

Com o meu salário comparado com a minha capacidade profissional.

Com a maneira como esta empresa realiza promoções de seu pessoal.

Com a capacidade de o meu trabalho absorver-me.

Com as oportunidades de ser promovido nesta empresa.

Com o entendimento entre eu e meu chefe. 


\begin{tabular}{|l|l|l|l|l|l|}
\hline Com meu salário comparado com meus esforços no trabalho. & & & & & \\
\hline Com a maneira como meu chefe trata-me. & & & & & \\
\hline Com a variedade de tarefas que realizo. & & & & \\
\hline Com a confiança que posso ter em meus colegas de trabalho. & & & & \\
\hline Com a capacidade profissional do meu chefe. & & & & \\
\hline
\end{tabular}

(c) Siqueira (1999)

POR FAVOR, preencha os dados a seguir. Eles são importantes para a estatística da pesquisa.

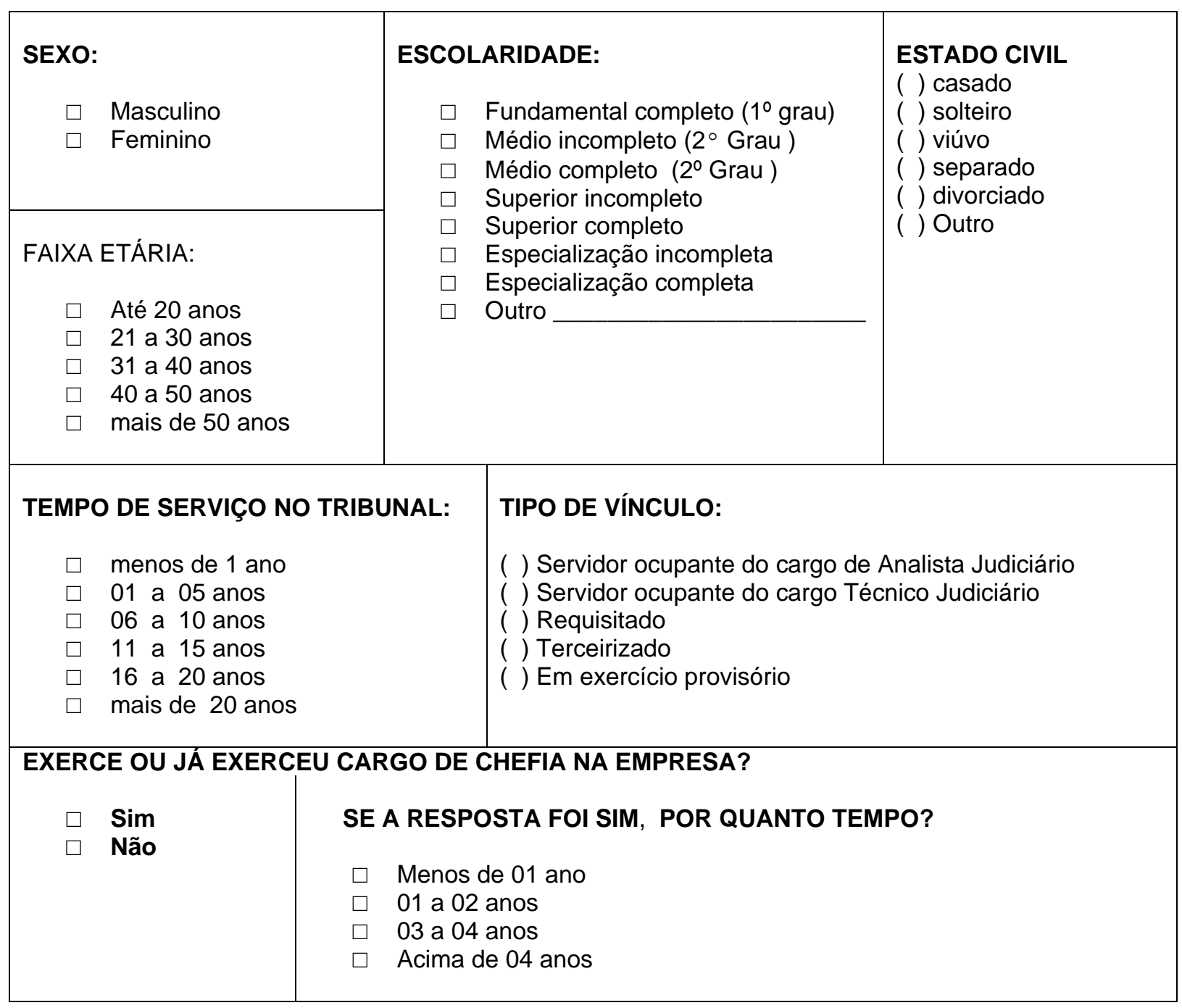

\section{Muito Obrigado}

